\title{
STUDIES ON THE PLASMA PROTEINS. ${ }^{1}$ V. THE EFFECT OF CON- CENTRATED SOLUTIONS OF HUMAN AND BOVINE SERUM ALBUMIN ON BLOOD VOLUME AFTER ACUTE BLOOD LOSS IN MAN
}

\author{
By JAMES T. HEYL, JOHN G. GIBSON, 2ND, AND CHARLES A. JANEWAY, with THE \\ TECHNICAL ASSISTANCE OF ANNE SHWACHMAN AND LADISLAS WOJCIK
}

(From the Medical Clinic of the Peter Bent Brigham Hospital and the Department of Medicine, Harvard Medical School, Boston)

(Received for publication August 19, 1942)

\section{INTRODUCTION}

Highly purified preparations of the various plasma proteins have recently been made available by Edwin J. Cohn and his colleagues in the Department of Physical Chemistry, Harvard Medical School. Sufficient quantities of human serum albumin have been prepared for an extensive clinical trial of its therapeutic action in traumatic shock (1). The crystallization of bovine serum albumin by Cohn and Hughes (2) has made this protein available for comparison in a state of even greater chemical purity.

In earlier papers of this series, the chemical properties of the serum albumins of bovine and human origin were described $(2,3)$. The differences between the size, shape, and net charge of these two proteins are so slight that mixtures behave like homogeneous solutions in both the ultracentrifuge and the electrophoresis apparatus. However, differences in chemical constitution and in crystallization conditions, as well as immunological tests, conducted in our laboratory, indicate that they are distinct proteins.

Scatchard, Batchelder, and Brown (4) have carried out a study of the osmotic pressure of serum albumin. No difference between albumins of bovine and human origin were found, as would be expected from the fact that their molecular weights and titration curves are closely similar. From comparative measurements made on serum

1 This work, supported by grants from the Rockefeller Foundation and from the Proctor and other funds of Harvard University, was aided early in 1941 by grants from the Committee on Medicine of the National Research Council. It has subsequently been carried out under a contract, recommended by the Committee on Medical Research, between the Office of Scientific Research and Development and Harvard University. albumin solutions and whole human serum, their calculations indicate that the osmotic pressure of 0.8 gram of albumin is equivalent to that of 1 gram of the normal mixture of plasma proteins.

Solutions of serum albumin offer practical advantages in the treatment of traumatic shock, particularly under military conditions. Since albumin is the most soluble and stable of the plasma proteins, it can be dispensed in a highly concentrated solution, which will withstand a fairly wide range of temperature. A 25 per cent solution has a low viscosity, so that it will pass readily through a Seitz filter for sterilization and can be injected easily through an ordinary intravenous needle by gravity. Thus, conservation of space, immediate availability for use without cross-matching, and ease of administration are among its assets (5). Furthermore, since albumin is largely responsible for the colloid osmotic pressure of normal plasma, and this pressure plays a major role in maintaining the volume of circulating plasma, it has seemed rational to use albumin in pure form to restore blood volume depleted by hemorrhage or plasma loss.

The experiments reported in this paper were planned in order to study quantitatively the physiologic effects of injections of concentrated solutions of serum albumin in man. ${ }^{2}$ They form part of a series of studies on shock, initiated in this clinic under the direction of Dr. Soma Weiss. Since it is generally agreed that the salient feature of traumatic shock is a diminution of the volume of circulating blood, it seemed important to study the response of normal human subjects to a measured loss of blood, produced by rapid venesection. A study of this response, carried out by

2 A brief report of these experiments and their implications has already appeared (6). 
Ebert, Stead, and Gibson (7), provided the background and technique for our investigations.

The first few experiments on the use of human and bovine albumin were performed by Stead and Ebert (8). These preliminary experiments proved that concentrated solutions of serum albumin were effective in replacing lost plasma. In the experiments to be reported below, we have attempted to determine the effectiveness of concentrated serum albumin with sufficient quantitative accuracy to justify comparison of its osmotic effect in vivo with that expected from the in vitro measurements of Scatchard, Batchelder, and Brown (4).

\section{MATERIALS AND METHODS}

The subjects for these experiments were normal adult males, in most cases medical students, whose intelligent cooperation has been extremely helpful. On the day preceding the experiment, the subject was admitted to the hospital soon after supper. The next morning, blood samples for the control plasma volume and other determinations were drawn. Following this, a rapid venesection of from 10 to 20 per cent of the total blood volume was performed, generally in 10 to 15 minutes. Blood

TABLE I

Quantitative data on amounts of blood removed and replaced in different experiments

\begin{tabular}{|c|c|c|c|c|c|c|c|c|c|c|c|c|c|}
\hline \multirow{3}{*}{ Subject } & \multicolumn{3}{|c|}{ Removal } & \multicolumn{3}{|c|}{ Replacement } & \multicolumn{4}{|c|}{ Plasma volumes } & \multirow{2}{*}{$\begin{array}{l}\text { Total } \\
\text { fluid } \\
\text { added }\end{array}$} & \multicolumn{2}{|c|}{$\begin{array}{l}\text { Fluid added or } \\
\text { retained by } 1 \\
\text { gram } ¥ \text { at } 1 \text { hour }\end{array}$} \\
\hline & Blood & Plasma & Protein & Volume & $\begin{array}{l}\text { Protein } \\
\text { conc. }\end{array}$ & Protein & Control & $\underset{\text { bleeding } t}{\text { After }}$ & $\begin{array}{c}\text { After } \\
\text { albumin }\end{array}$ & $\begin{array}{l}\text { Time } \\
\text { after } \\
\text { albumin }\end{array}$ & & Average & Average \\
\hline & $c c$. & ce. & grams & $c c$. & $\begin{array}{l}\text { grams } \\
\text { per cent }\end{array}$ & grams & $c c$. & cc. & $c c$. & hours & $c c$. & $\begin{array}{l}c c . \text { per } \\
1 \text { gram }\end{array}$ & $\begin{array}{l}\text { cc. per } \\
1 \text { gram, } \\
1 \text { hour }\end{array}$ \\
\hline
\end{tabular}

A. Experiments performed under conditions of dehydration (No food or fluid for 12 hours preceding and 12 to 24 hours after venesection)

1. Control

\begin{tabular}{l|l|l|l|l|l|l|l|l|l|l|l|l|l|}
\hline M. Be. & 527 & 291 & 18.9 & 0 & & 0 & 2780 & 2489 & 2440 & 1 & \\
& & & & & & 40 hours dehydrated & 2750 & 20 & 261 & \\
\hline
\end{tabular}

2. Replacement with reconstituted dried human plasma

\begin{tabular}{l|l|l|l|l|l|l|l|l|l|l|l|l|l|}
\hline Rh. & 840 & 470 & 32.0 & 607 & 5.3 & $\begin{array}{c}32.0 \\
40 \text { hours dehydrated } \\
\text { Normal hydration }\end{array}$ & $\begin{array}{l}3090 \\
3930\end{array}$ & $\begin{array}{c}20 \\
72\end{array}$ & $\begin{array}{l}650 \\
130\end{array}$ & 20.3 & 970 & \\
\hline
\end{tabular}

3. Replacement with human albumin

\begin{tabular}{l|r|r|r|r|r|r|l|l|l|l|l|l|l|l}
\hline W. B. & 1028 & 550 & 36 & 170 & 22.8 & 38.8 & 3490 & 2940 & 3450 & $1 \frac{1}{2}$ & 510 & 13.2 & \\
W. M. & 780 & 433 & 29 & 167 & 25.2 & 42.0 & 2960 & 2527 & 3280 & $\frac{1}{2}$ & 753 & 17.9 & \\
A. L. & 745 & 425 & 26 & 140 & 21.0 & 29.4 & 3030 & 2605 & 3210 & 1 & 605 & 20.5 & 17.2 \\
& & & & & & & & & & & & & 17.5 \\
\hline
\end{tabular}

4. Replacement with crystallized bovine albumin

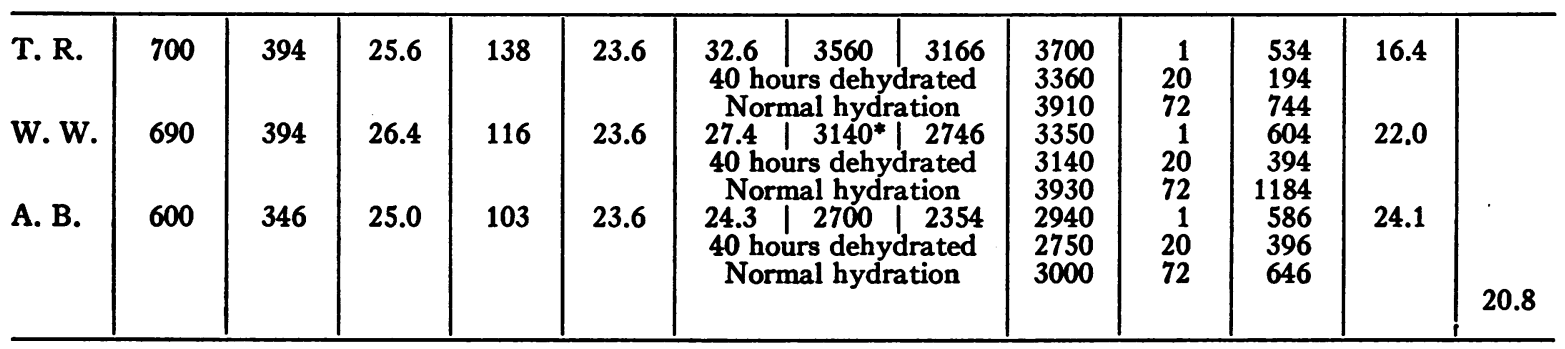


TABLE I-(Continued)

\begin{tabular}{|c|c|c|c|c|c|c|c|c|c|c|c|c|c|}
\hline . & \multicolumn{3}{|c|}{ Removal } & \multicolumn{3}{|c|}{ Replacement } & \multicolumn{4}{|c|}{ Plasma volumes } & \multirow{2}{*}{$\begin{array}{l}\text { Total } \\
\text { fluid } \\
\text { added }\end{array}$} & \multicolumn{2}{|c|}{$\begin{array}{l}\text { Fluid added or } \\
\text { retained by } 1 \\
\text { gram } \ddagger \text { at } 1 \text { hour }\end{array}$} \\
\hline Subject & Blood & Plasma & Protein & Volume & $\begin{array}{l}\text { Protein } \\
\text { conc. }\end{array}$ & Protein & Control & $\begin{array}{c}\text { After } \\
\text { bleeding } \dagger\end{array}$ & $\begin{array}{l}\text { After } \\
\text { albumin }\end{array}$ & $\begin{array}{c}\text { Time } \\
\text { after } \\
\text { albumin }\end{array}$ & & Average & Average \\
\hline & $c c$ & cc. & grams & $c c$. & $\begin{array}{c}\text { grams } \\
\text { pet cent }\end{array}$ & grams & $c c$. & $c c$. & ce. & hours & ce. & $\begin{array}{l}\text { cc. per } \\
1 \text { gram }\end{array}$ & $\begin{array}{l}c c . \text { per } \\
1 \text { gram, } \\
1 \text { hour }\end{array}$ \\
\hline
\end{tabular}

B. Experiments performed under conditions of normal hydration

Replacement with human albumin

\begin{tabular}{|c|c|c|c|c|c|c|c|c|c|c|c|c|c|}
\hline $\begin{array}{l}\text { M. Be. } \\
\text { M. Bo. }\end{array}$ & 1085 & 517 & $\begin{array}{r}34.6 \\
42.7\end{array}$ & 134 & $\begin{array}{r}23.8 \\
27.0\end{array}$ & $\begin{array}{l}31.9 \\
65.0\end{array}$ & $\begin{array}{r}2640 \\
3780\end{array}$ & $\begin{array}{l}2123 \\
3195\end{array}$ & $\begin{array}{l}2640 \\
2500 \\
3000 \\
4060 \\
3800 \\
4280\end{array}$ & $\begin{array}{r}1 \\
20 \\
72 \\
1 \\
20 \\
72\end{array}$ & $\begin{array}{r}517 \\
377 \\
877 \\
865 \\
605 \\
1085\end{array}$ & 16.2 & 14.8 \\
\hline
\end{tabular}

C. Experiments performed under conditions of forced hydration (Forced fluids by mouth with 10 to 14 grams of additional salt as tablets)

Replacement with crystallized bovine albumin

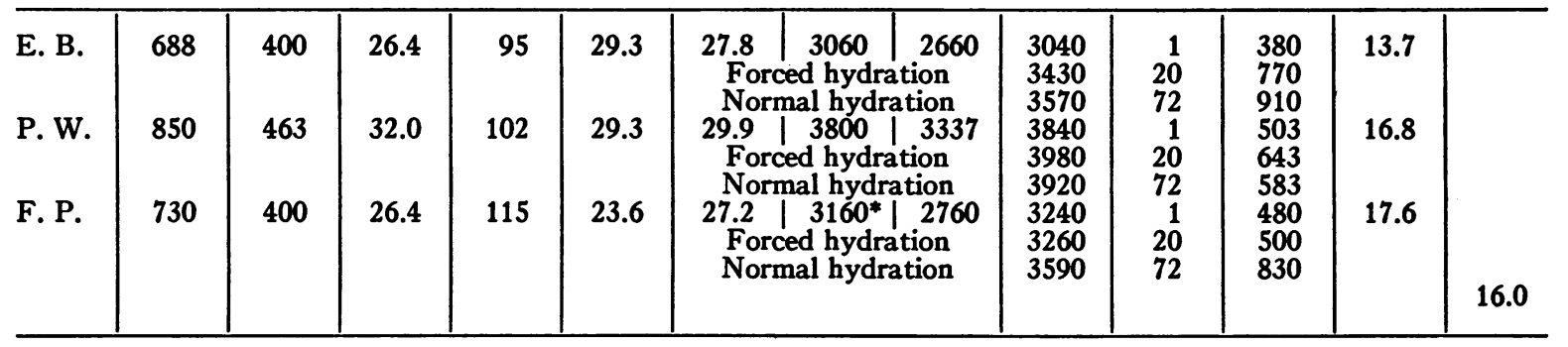

* Estimated from height because of technical errors.

Taking average of 11 men: 17.4

† Calculated by subtracting the plasma bled from the control volume.

$\ddagger$ Total fluid added to plasma volume since bleeding, divided by the grams of injected protein.

samples were taken, and the albumin injection was started immediately afterwards. This required from 20 to 40 minutes in different experiments. Blood samples were taken at appropriate intervals, and 1 hour after the completion of the injection, a second measurement of the plasma volume was made. Subjects remained in the hospital until the following morning, when the plasma volume was again determined. They were then discharged, but returned 48 hours later for a final (fourth) plasma volume determination. All subjects were followed carefully for 3 months. In different experiments, the size of the venesection, the state of hydration of the subject, and the type of concentrated serum albumin injected, varied.

Plasma volume determinations were made according to the method of Gibson and Evans (9), using Gibson and Evelyn's adaptation of the method to the photoelectric colorimeter (10). Eight to $10 \mathrm{cc}$. of dye ( 0.1 per cent) were injected intravenously from a calibrated syringe. Eighteen to 20 minutes later, a series of 5 samples of venous blood was drawn without stasis at 5-minute intervals. The dye was reinjected for each successive plasma volume determination in each subject.
Experiments were performed only after a night in the hospital. Subjects were up on their feet for a few minutes on the morning of the experiment, but then were recumbent for an hour or more before actual tests were begun. ${ }^{3}$ On follow-up visits they remained recumbent for at least 20 minutes before blood was drawn. ${ }^{3}$ Samples were drawn into dry, sterile syringes, approximately 60 seconds after the release of the tourniquet, to avoid the complications introduced by stasis secondary to venous occlusion. One cc. of blood was mixed with a small amount of dry potassium oxalate in each of 2 tubes, and the oxyhemoglobin determinations made in duplicate from these, using the Klett-Summerson photoelectric colorimeter. Hematocrit readings were determined by adding $4 \mathrm{cc}$. of blood to $1 \mathrm{cc}$. of 1.6 per cent potassium oxalate solution in special graduated $5 \mathrm{cc}$. tubes, which were spun 30 minutes at 3000 r.p.m. in an International centrifuge with a head $26 \mathrm{~cm}$. in diameter.

${ }^{8}$ The importance of these precautions, pointed out to us by Stead and Ebert, has been clearly indicated in a recent paper by Perera and Berliner (11). 


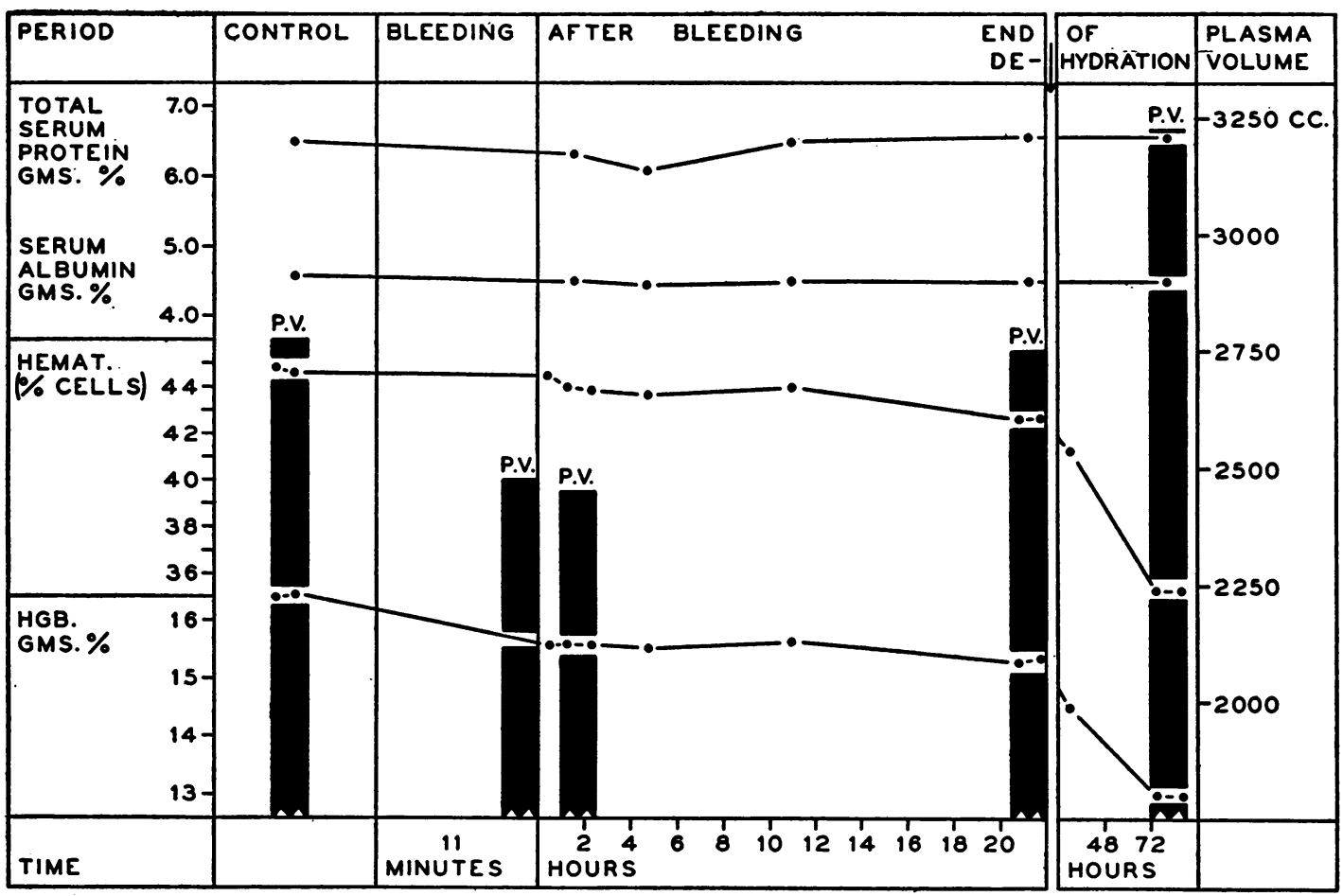

Fig. 1. Venesection Without Albumin-Dehydration-Control

Normal subject (M. Be.), bled 10.5 per cent of circulating plasma volume, used as a control. No food or fluid for 16 hours preceding and 24 hours following venesection. Weight loss, $2.3 \mathrm{kgm}$.

The blood removed at venesection was measured in a 1000 cc. graduate, the volume of citrate anticoagulant being deducted; the $50 \mathrm{cc}$. of blood removed in the control plasma volume determination was added to that removed by rapid venesection to obtain the measured total blood loss.

Non-protein nitrogen and total serum protein determinations were made by $\mathrm{Kjeldahl}$ digestion and direct nesslerization. Albumin was determined by salting out the globulins by the Howe method (12) and Kjeldahl digestion of the filtrate. These tests were performed in duplicate.

The solutions of serum albumin used in these experiments were prepared under the supervision of Professor Cohn and his associates. The human serum albumin was fractionated and purified by L. E. Strong, J. L. Oncley, and their co-workers at the Harvard Plasma Fractionation Laboratory, and was then sterilized and bottled under the direction of Drs. Elliott Robinson and Geoffrey Edsall at the Massachusetts Antitoxin and Vaccine Laboratory. The bovine plasma was fractionated by the same methods under the direction of Dr. J. D. Porsche at the Armour Laboratories, Chicago, and crystallized by Professor Cohn and Dr. W. L. Hughes, Jr., at the Harvard Pilot Plant. The albumin was dissolved in physiological saline solution (ionic strength $0.15 \mathrm{M}$ ), buffered with sodium bicarbonate to a $\mathrm{pH}$ varying from 6.0 to 7.4 in different preparations. Its final concentration was approximately 25 per cent and was measured by Kjeldahl nitrogen determination. The solutions were sterilized by Seitz filtration. Merthiolate was added to a final concentration of $1: 10,000$ to the solutions of human albumin, but no preservative was used in the bovine albumin solution. All the preparations of albumin were tested in convalescent patients, in doses up to 25 grams, for the presence of pyrogens, before being used in these experiments.

\section{RESULTS}

\section{A. Acute experiments}

1. Control. Venesection and dehydration. Since we used a more vigorous regime of dehydration than Ebert, Stead, and Gibson (7), it was necessary to supplement their experiments with a further study of the effects of venesection in a subject deprived of food and water for 16 hours before and 24 hours after bleeding. The data, presented in Table I (A.1) and in Figure 1, are self-explanatory. The diminished plasma volume following venesection slowly and steadily increased with a rapid increment when salt and water were administered orally. 


\section{Control. Venesection and replacement with} human plasma; dehydration. As a further control, the effect of reconstituted dried human plasma was studied for comparison with concentrated albumin (Table I, A.2; Figure 2). As was to be expected, $607 \mathrm{cc}$. of human plasma (protein content 5.3 grams per cent) produced prompt hemodilution, due to an increase of the plasma volume. Subsequently, with continued dehydration, hemoconcentration developed, which was relieved when the fluid intake became normal.

3. Venesection and replacement with concentrated albumin solutions (25 per cent). These experiments are arranged in groups according to the state of hydration of the subject and the type of concentrated albumin injected. The data are presented in Table I, with sample experiments from the groups represented in Figures 3 and 4. By "normal hydration" is meant an intake of fluid as desired while on a low caloric diet, free of fat. The state referred to as "dehydration" consisted of 40 hours without food or water; of this period, 12 to 16 hours preceded the injection of albumin, and 20 to 24 hours followed. During "forced hydration," 2 grams of sodium chloride were given by mouth at 4-hour intervals to a total of 10 to 14 grams, while fluids totalling 2,000 to $4,000 \mathrm{cc}$. were taken by mouth, except during the 4 hours required for the plasma volume determinations, venesection, and albumin injection. The concentration of albumin, as injected, was approximately 25 per cent in an isotonic buffered saline solution.

Comparison of the results in groups A.3 and A.4 (Table I) shows that there was no significant difference between the responses observed at 1 hour after the injection of human or bovine albumin. Figures 3 and 4 illustrate this similarity, although the size of the venesections and state of hydration were not strictly comparable. In each case, the plasma volume increased promptly following the administration of concentrated albumin, as shown by a fall in the values for hemoglobin and hematocrit and a rise in the plasma volume, as determined by the dye method. This rise in all cases was considerably greater than the volume of the concentrated albumin solution injected, indicating that extra fluid had been added to the circulating plasma from the body's own reserves.

The experiments in group $\mathrm{C}$ were devised for
TABLE II

Sodium and potassium studies in normal subjects after venesection of 10 to 20 per cent of the blood volume, followed by injection of albumin as 25 per cent solution. No food intake; normal or limited water intake

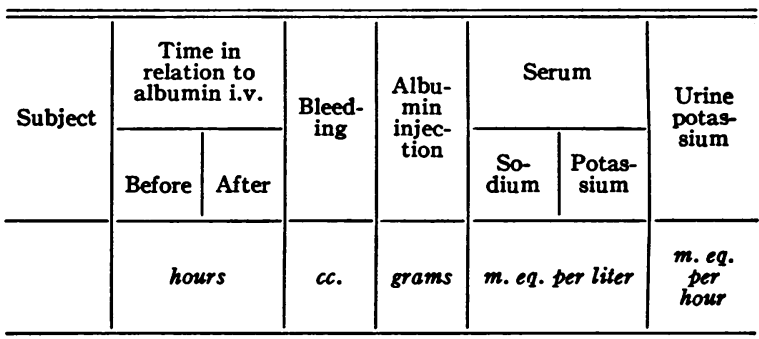

A. Subjects dehydrated for $\mathbf{1 5}$ hours preceding and 20 hours following albumin

\begin{tabular}{c|c|c|c|c|c|c|c}
\hline $\begin{array}{c}\text { M. Be. } \\
\text { (con- }\end{array}$ & 1 & & 527 & 0 & 143.9 & 4.5 & \\
trol) & & 20 & & & 143.8 & 4.4 & \\
T. R. & 1 & & 700 & 33 & 145 & 5.4 & \\
& & 1 & & & 146 & 4.6 & \\
& & 20 & & & 140 & 10.1 & 2.4 \\
W. W. & 1 & & 690 & 26 & 144 & 4.5 & \\
& & $1 \frac{1}{2}$ & & & 144 & 4.5 & \\
& & 20 & & & 145 & 4.7 & 1.5 \\
A. B. & 1 & & 600 & 24 & 138 & 4.9 & \\
& & $1 \frac{1}{2}$ & & & 140 & 4.8 & \\
\end{tabular}

B. Subjects without food intake but normal hydration

\begin{tabular}{l|r|r|r|r|r|r|r}
\hline M. Be. & 1 & & 912 & 32 & 141.2 & 4.5 & 5.5 \\
& & $1 \frac{1}{2}$ & & & 143.9 & 4.2 & 3.7 \\
M. Bo. & 1 & & \multirow{3}{*}{1085} & 65 & 145.1 & 2.9 & 3.2 \\
& & 2 & & & 146.9 & 3.7 & 4.4 \\
\hline
\end{tabular}

comparison with those of groups A.3 and A.4, to determine whether mild dehydration would alter the response to concentrated albumin. That there was no significant difference between the responses observed at 1 hour, under conditions of relative dehydration or under conditions of forced hydration, is obvious from the comparison. In Figure 5 , the responses of hydrated and relatively dehydrated subjects are compared graphically on a scale, using percentage deviation from the normal starting values. The average values for the 3 subjects in each of groups A.4 and C are used. The responses charted for the control subject who was dehydrated, but received no albumin, represent the results in a single individual (Figure 1 ; Table I, A.1). The chart is therefore not subject to 


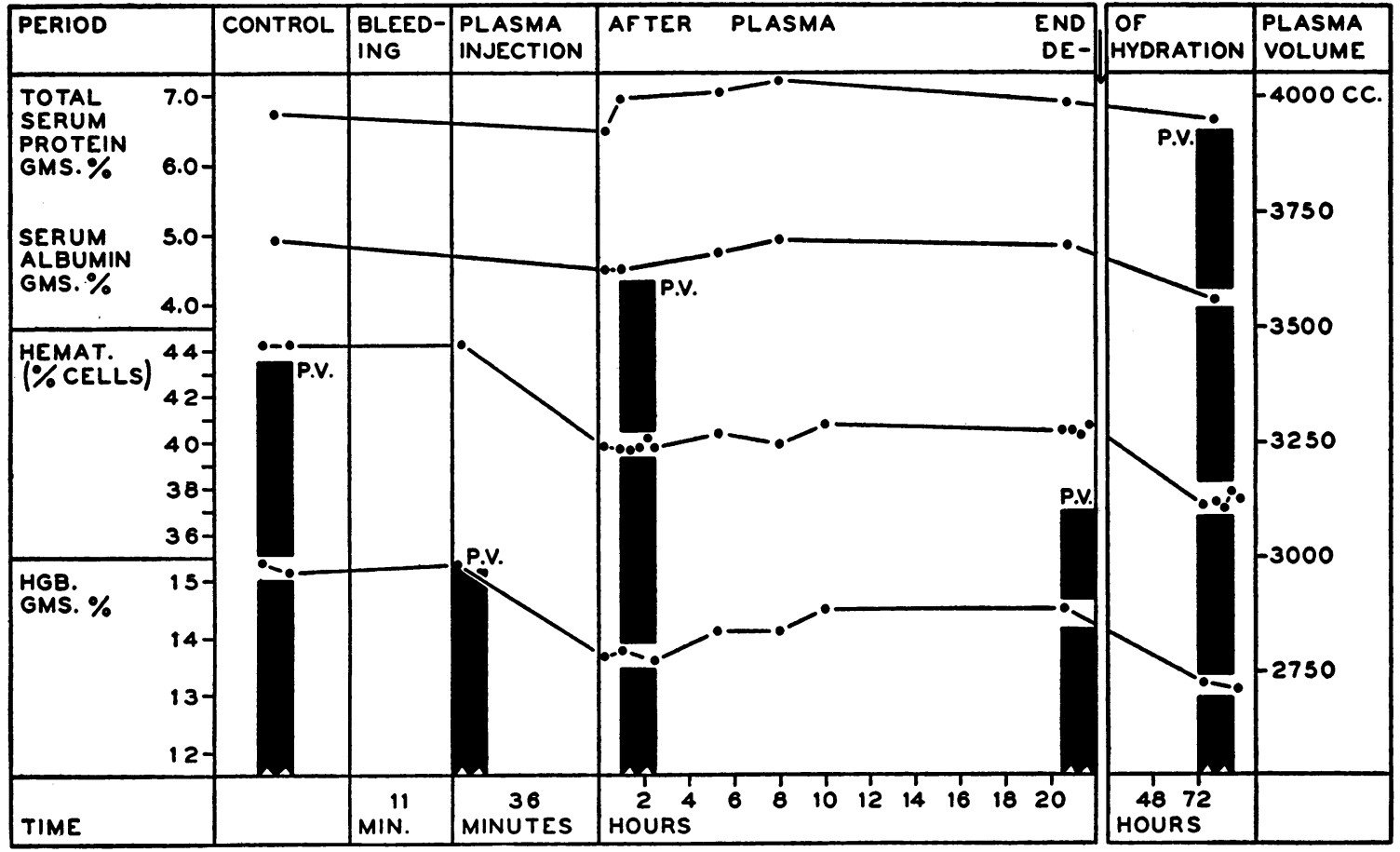

Fig. 2. Reconstituted Human Plasma After Venesection-Dehydration

Normal subject (Rh.), bled 13.7 per cent of circulating plasma volume, followed by injection of 607 cc. (containing 5.3 per cent plasma protein, or 32 grams) reconstituted dried human plasma (citrated). No food or water for 16 hours preceding and 24 hours following venesection.

strict interpretation, but does indicate trends that were consistent. The differences observed were those to be expected in any group of normal individuals. Those who were kept dehydrated after albumin injection showed progressive, mild hemoconcentration, finally interrupted by the administration of fluid, while those given excess quantities of salt and water showed hemodilution. Neither group displayed untoward symptoms.

A study was made of the potassium in the serum and urine of 4 dehydrated subjects and 2 subjects who were normally hydrated but who submitted to larger venesections and injections. The determinations were performed through the kindness of Dr. James L. Gamble. ${ }^{4}$ The results are shown in Table II. There was no increase in serum potassium 1 hour after the injection of albumin was completed. In only 1 subject (T. R.) was there a rise after 40 hours' dehydration, 20 hours after the administration of albumin, al-

4 Miss E. A. MacLachlan and Miss K. R. Fahey performed the determinations. though the subject was ambulatory and asymptomatic. The potassium output in the urine was not significantly increased in the 24 hours following albumin injection. Therefore, in neither urine nor serum was there evidence of mobilization of potassium from the cells.

\section{B. Follow-up studies}

The subjects were carefully followed, at frequent intervals, for 3 to 4 months in order to rule out possible harmful effects of the concentrated albumin solutions. All subjects were given a complete physical examination before the experiment and at the end of the follow-up period, as well as a number of interim examinations. Complete urinalysis and blood examinations were included and in a few cases reticulocyte counts were made during the first 2 weeks after bleeding. The physical findings have not been abnormal in any of the subjects, before or after the experiments. Urinalysis by ordinary methods failed to show any proteinuria after the injections. Even when extremely sensitive precipitin tests, using potent 


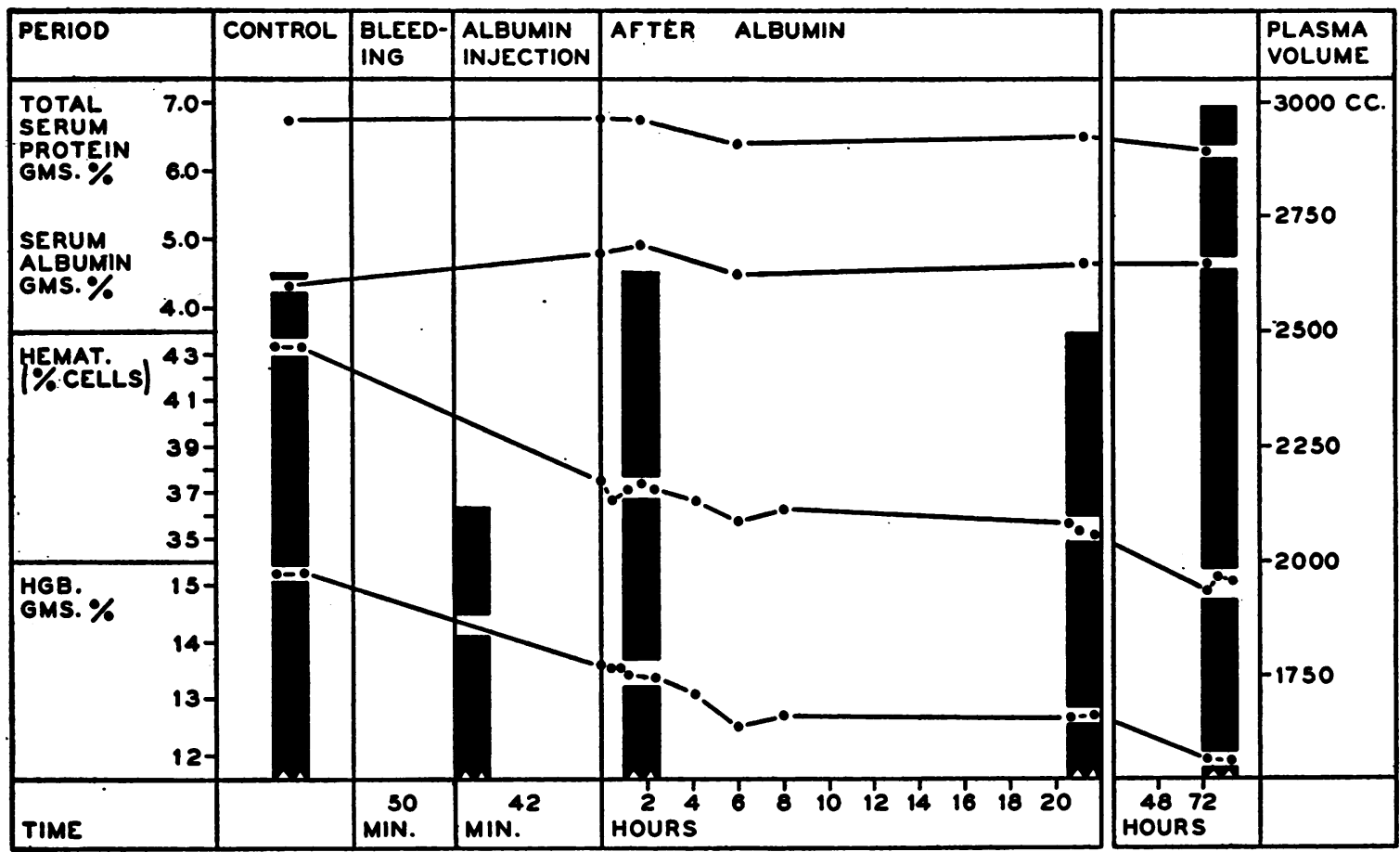

Fig. 3. Concentrated Human Albumin After Venesection-Normal Hydration

Normal subject (M. Be.), bled 19.5 per cent of circulating plasma volume, followed by injection of 32 grams (134 cc. of 24 grams per cent) of human serum albumin. Normal food and fluid intake except during 4 hours of procedure.

rabbit antisera, were performed, a trace was found, during the period soon after injection, in the urine of only 1 subject receiving bovine albumin. No abnormalities of the sediment were noted. Marked concentration of the urine occurred during the period of dehydration and subsequent hydration until the fluid deficit was restored.

We were particularly concerned with the rate of blood regeneration. The time required for the hematocrit and hemoglobin values to return to their prebleeding levels varied in different subjects. In all, however, approximately normal values were restored in 8 weeks or less. Ferrous sulfate, in doses of 0.2 gram, 3 times a day, was administered to all for the first 3 weeks in order to provide an adequate supply of iron for hemoglobin formation. The maximum reticulocyte responses varied from 1.5 to 3.2 per cent in the 7 subjects tested and were seen 4 to 10 days after bleeding. This was comparable to the reticulocyte response to bleedings of similar size in 4 transfusion donors who received no albumin. There was no depression of the level of serum protein or of serum albumin in this period.

\section{DISCUSSION}

The injection of concentrated albumin, at rates of approximately $5 \mathrm{cc}$. per minute, was tolerated in almost all subjects without any untoward symptoms. With 2 preparations of human albumin, some epigastric and precordial distress was noted, but these were prepared by a different technique, as an experiment. With no preparation of either human or crystallized bovine albumin, made according to the standard procedures that have now been developed, has discomfort been noted during the injection. Some subjects complained of a slight metallic taste "like kerosene," but this was never noted with any preparation which did not contain merthiolate, and presumably was due to that substance. Two or 3 urticarial wheals appeared in a few subjects given bovine albumin, but these were also observed when reconstituted dried human plasma was used; none was noted with human albumin. On the whole, the injection 


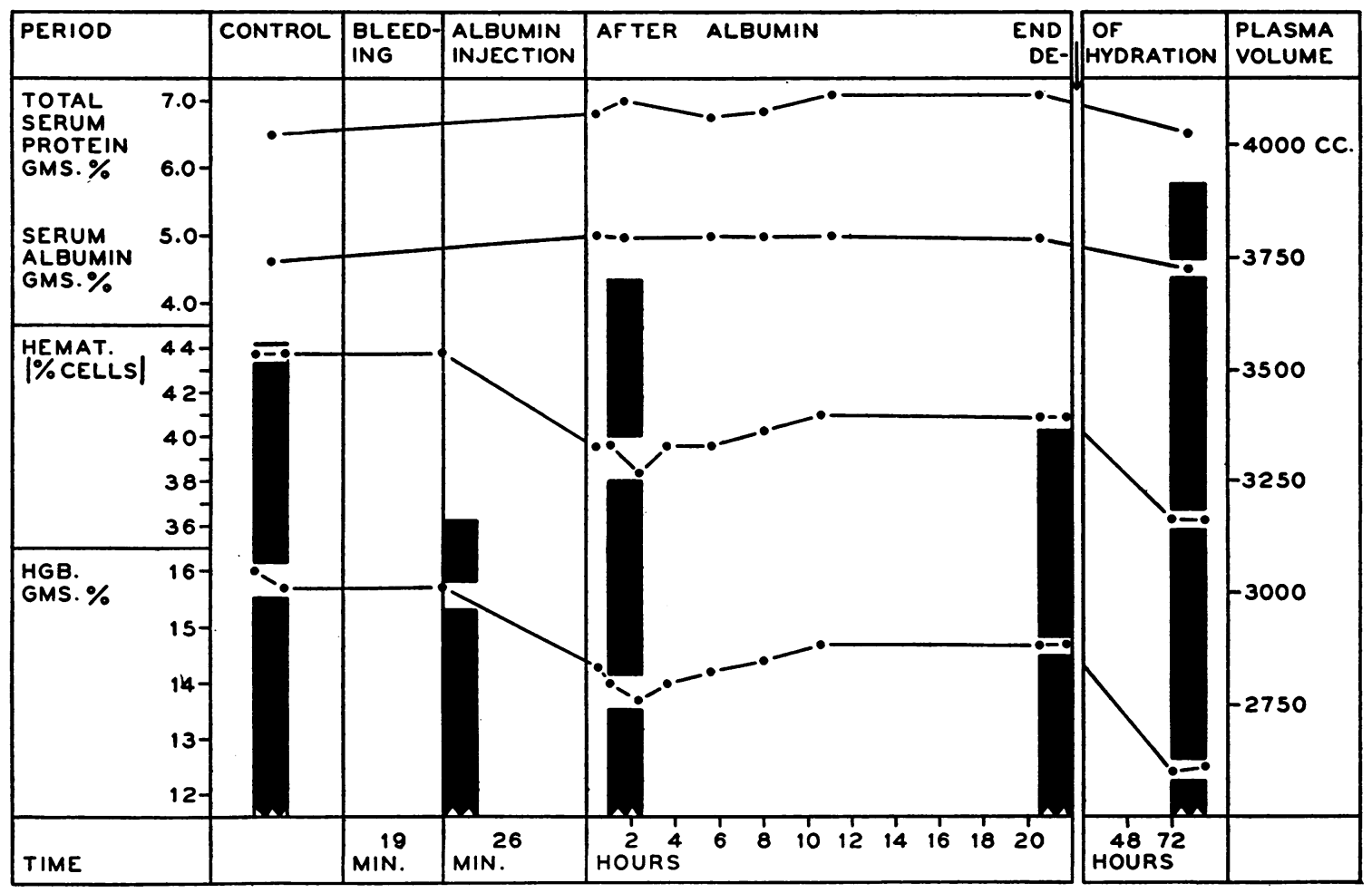

Fig. 4. Concentrated Bovine Albumin After Venesection-Dehydration

Normal subject (T. R.), bled 11.0 per cent of circulating plasma volume, followed by injection of 33 grams (138 cc. of 23.6 grams per cent) of crystallized bovine serum albumin. No food or fluid intake for 16 hours preceding and 24 hours following venesection. Weight loss, $2.4 \mathrm{kgm}$.

of concentrated albumin solutions seemed simple and safe under the circumstances of the experiments.

We shall not discuss the immunologic problems raised by the administration of bovine albumin. These have been considered in another communication in a preliminary manner (13), but no final conclusions can be drawn until much more extensive experiments with crystallized preparations of low globulin content have been completed in order to determine to what extent it will be safe to use a protein of animal origin for therapy in man.

The rapidity with which hemodilution occurred following the administration of concentrated albumin solutions was very striking. Most of the changes had already taken place within 15 minutes after the cessation of the injection, but further hemodilution occurred slowly for a period of an hour or so. The plasma volume was determined about 1 hour after injection to allow for this, but no later, in order that the changes found could be ascribed to the albumin injected and not to the regeneration of plasma protein by the patient himself.

One objection that might conceivably be raised to our use of the hematocrit as an index of immediate changes is that lowering of the hematocrit value may have been due to shrinkage of the red cells produced by the hypertonic albumin solution. However, the hemoglobin values ran parallel to the hematocrit readings, and the plasma itself became only slightly hypertonic according to the serum protein values. Furthermore, suspensions of equal quantities of red cells, in albumin solutions of from 5 to 10 per cent concentration, have been prepared, and these have all given the same hematocrit reading.

The effect of the injection of concentrated albumin on the values for the blood proteins was about as expected, allowing for inevitable errors in the methods for their measurement. Fifteen minutes after injection, the plasma protein value 


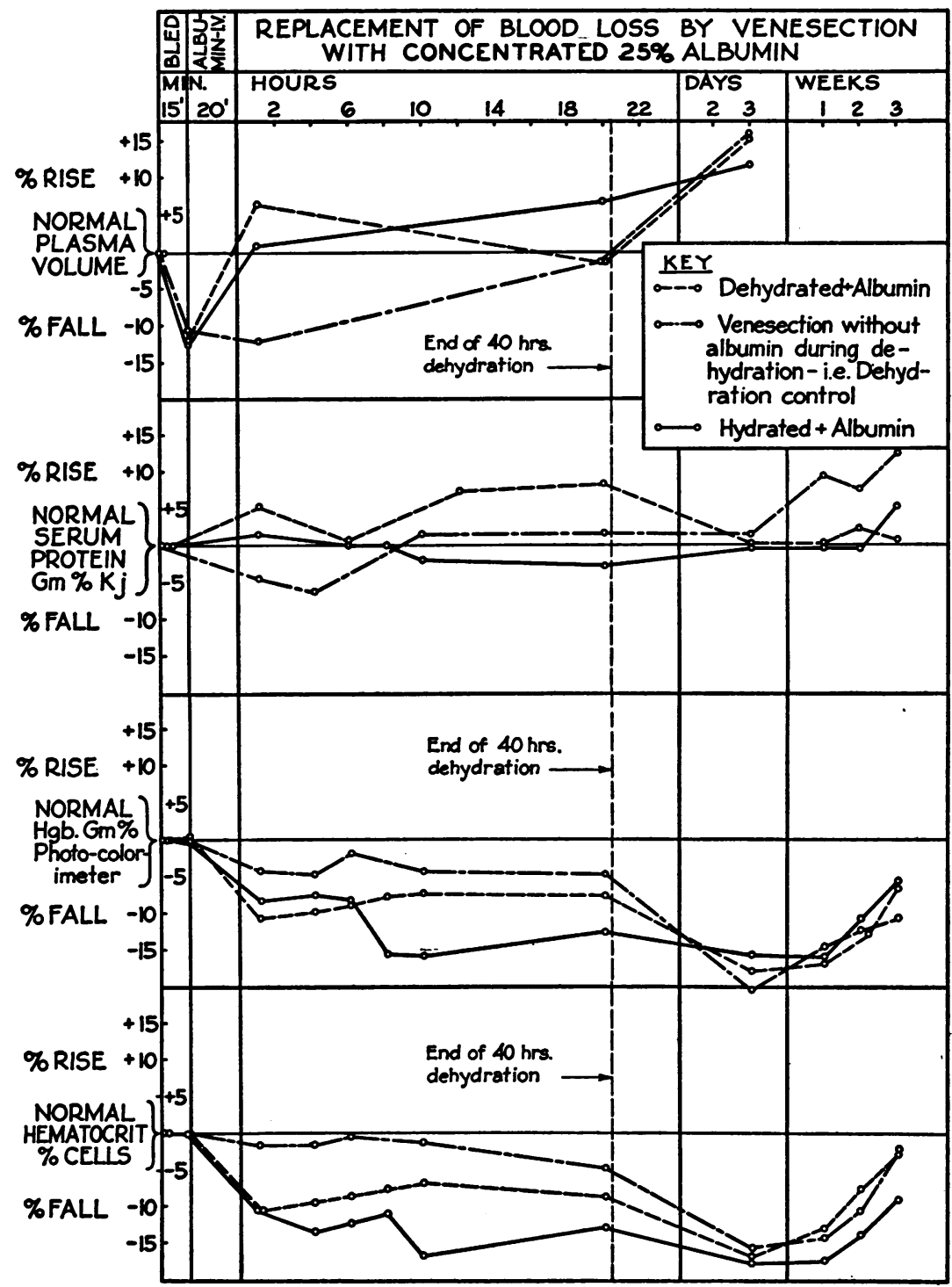

Fig. 5. Composite Chart to Compare Groups A.4 and C.1

The average values for the 3 subjects in each group are plotted against the values for the single dehydrated subject used as a control. The scale used is one of percentage deviation from the normal starting values for each subject. All subjects except the control received crystallized bovine albumin. There was no fluid intake in any subject during the 4-hour experimental period, beginning with the first plasma volume determination.

tended to be higher than before, with the increase in the albumin fraction. Within an hour, the protein value usually fell back toward normal, but the proportion of albumin to globulin returned to normal more slowly, often requiring as much as 24 hours. There was no essential difference in this response with either bovine or human albumin. Later determinations of the serum pro- tein values, over the 3 to 4 months' follow-up period, showed no decrease of serum albumin nor increase in serum globulin values, such as one might expect had liver damage occurred from the injection of either homologous or heterologous protein in such high concentrations. The serum concentration of bovine albumin was carefully followed by quantitative immunologic measurements, 
which will be reported subsequently. It disappeared from the blood stream gradually over a period of several months.

An attempt has been made to correlate our experiments with the previously mentioned studies of Scatchard, Batchelder, and Brown (4) on the osmotic pressures of serum and serum albumin. For this purpose, we calculated from our data the amount of fluid added to the plasma in 1 hour by the injection of a given dose of concentrated albumin. This value was divided by the number of grams injected to obtain a figure for the number of cc. of fluid added to the plasma by each gram of albumin injected. These values appear in the last column in Table I and vary from 13.2 to 24 cc. in all experiments, with an average of $17.4 \mathrm{cc}$.

Scatchard and his associates (4) found that 0.8 gram of albumin exerted the same osmotic pressure as $1 \mathrm{gram}$ of total plasma protein. The average serum protein figure in our subjects was 6.8 grams per cent, which with 0.2 gram per cent fibrinogen would give an estimated circulating plasma protein figure of 7 grams per cent. Using the ratio, $\frac{0.8 \text { albumin }}{1 \text { plasma protein }}$, a 5.6 per cent albumin solution should be isosmotic with such a plasma. On this basis, each gram of albumin injected would be expected to add $18 \mathrm{cc}$. of fluid to the circulation. The close correspondence of our findings in vivo with the expected findings based on accurate in vitro measurements is very gratifying. The errors inherent in our methods, particularly the determination of plasma volume, are considerable. However, the number of experiments is sufficient to give a fairly valid average, and the trends in all the experiments are consistent. The fact that both in vitro and in vivo measurements give essentially the same results indicates that the ability of albumin to draw fluid into the circulation may be predicted fairly accurately from its in vitro osmotic pressure, provided the capillary permeability is normal. The combined data form the basis for the arbitrary selection of 25 grams of serum albumin in $100 \mathrm{cc}$. of buffered saline as the standard, unit dose. Because each gram should add $18 \mathrm{cc}$. of fluid to the circulation, this dose is approximately equivalent to $450 \mathrm{cc}$. of normal circulating plasma, or $500 \mathrm{cc}$. of citrated plasma, as usually prepared.
No conclusion may be drawn from these experiments that solutions of concentrated albumin are necessarily superior to isosmotic solutions, but evidence is presented to show that concentrated solutions of albumin will draw fluid into the blood stream rapidly without doing harm, after blood loss and relatively mild dehydration. It is worthwhile to point out certain differences between these concentrated albumin solutions and 4-times concentrated plasma $(14,15)$. The viscosity of concentrated plasma is much greater than that of concentrated albumin, because of the presence of the globulins (16). The total osmotic pressure of concentrated plasma is far greater, because of the presence of concentrated electrolytes, while the salt concentration in our albumin solutions, as now prepared, is approximately isotonic. However, the colloid osmotic pressure of 25 per cent albumin solution is greater than that of 4-times concentrated plasma. These and other chemical differences may necessitate a separate evaluation of the physiologic response to the 2 agents.

It is obvious that albumin solutions lack many important functional constituents of plasma, which are present in the globulin fractions. These deficiencies probably make it unwise to administer albumin in very large doses, repeatedly, over a short period of time. However, in emergencies, albumin solutions have great practical advantages in their instant availability, ease of administration, and potency in restoring the colloid osmotic pressure, and thus the circulating blood volume.

\section{SUMMARY}

Concentrated solutions of human and crystallized bovine albumin were injected into normal subjects after removal of 10 to 20 per cent of the blood volume by venesection. Their state of hydration was varied: Quantitative measurements of the changes in plasma volume were made by means of the dye method and by repeated determinations of the values for serum protein, hemoglobin, and hematocrit reading. The measurements indicated that:

1. Concentrated albumin solution (25 per cent) would draw fluid into the blood stream.

2. Each gram of albumin drew an average of $17.4 \mathrm{cc}$. of fluid into the circulation in an hour, in 11 subjects, with a spread of 13.2 to 24 cc. This 
is in good agreement with the value expected from in vitro studies of the osmotic pressure of human and bovine serum albumin. The in vitro and in vivo measurements together form the basis for the selection of the unit dose of 25 grams of albumin, which should add to the circulation a volume of fluid equivalent to $450 \mathrm{cc}$. of circulating plasma or $500 \mathrm{cc}$. of citrated plasma.

3. Mild variations in the state of hydration did not affect the availability of this fluid.

4. The serum and urinary potassium values were not significantly increased following the injection of concentrated albumin solutions under the conditions of these experiments.

5. No significant immediate or delayed harmful effects were observed in the subjects, who were carefully followed for a period of 3 months after the injection of albumin.

6. No essential difference was observed between human and crystallized bovine albumins in their ability to draw fluid into the circulation.

7. There is ample evidence that concentrated human albumin is a safe and effective therapeutic agent. No statement regarding the safety for intravenous use of crystallized bovine serum albumin of low globulin content can be made until more extensive clinical tests have been completed in order to determine to what extent and under what circumstances it will be safe to use a protein of animal origin for therapy in man.

Inclusion of this paper in this number of the Journal of Clinical Investigation was made possible by the Josiah Macy, Jr. Foundation, at the request of the editors, in order to provide prompt publication of results of investigation particularly relevant to military medicine.

\section{BIBLIOGRAPHY}

1. Woodruff, L. M., and Gibson, S. T., The use of human albumin in military medicine. Part II. The clinical evaluation of human albumin. U. S. Nav. M. Bull., 1942, 40, 791.

2. Cohn, E. J., and Hughes, W. L., Jr., To be published.

3. Cohn, E. J., Oncley, J. L., Strong, L. E., Armstrong, S. H., Ferry, R. M., and Hughes, W. L., Jr., Properties and functions of the purified proteins of animal and human plasmas. Chapter XX in "Blood
Substitutes and Blood Transfusion" by S. Mudd and $\mathrm{W}$. Thalhimer, Charles C. Thomas Publisher, Springfield, Ill., 1942.

4. Scatchard, G., Batchelder, A. C., and Brown, A., To be published.

5. Newhouser, L. R., and Lozner, E. L., The use of human albumin in military medicine. Part III. The standard Army-Navy package of serum albumin human (concentrated). U. S. Nav. M. Bull., 1942, 40, 796.

6. Heyl, J. T., and Janeway, C. A., The use of human albumin in military medicine. Part I. The theoretical and experimental basis for its use. U. S. Nav. M. Bull., 1942, 40, 785.

7. Ebert, R. V., Stead, E. A., Jr., and Gibson, J. G., 2nd, Response of normal subjects to acute blood loss. Arch. Int. Med., 1941, 68, 578.

8. Stead, E. A., Jr., and Ebert, R. V., Studies on human albumin. Section in "Blood Substitutes and Blood Transfusion" by S. Mudd and W. Thalhimer, Charles C. Thomas Publisher, Springfield, Ill., 1942, p. 185.

9. Gibson, J. G., 2nd, and Evans, W. A., Jr., Clinical studies of the blood volume. I. Clinical application of a method employing the azo dye "Evans blue" and the spectrophotometer. J. Clin. Invest., 1937, 16, 301.

10. Gibson, J. G., 2nd, and Evelyn, K. A., Clinical studies of the blood volume. IV. Adaptation of the method to the photoelectric microcolorimeter. J. Clin. Invest., 1938, 17, 153.

11. Perera, G. A., and Berliner, R. W., The relation of postural hemodilution to paroxysmal dyspnea. J. Clin. Invest., 1943, 22, 25.

12. Howe, P. E., The use of sodium sulfate as the globulin precipitant in the determination of proteins in blood. J. Biol. Chem., 1921, 49, 93.

13. Janeway, C. A., Immunological and clinical studies on purified proteins of human and animal plasma. Chapter XXI in "Blood Substitutes and Blood Transfusion" by S. Mudd and W. Thalhimer, Charles C. Thomas Publisher, Springfield, Ill., 1942, pp. 184-199.

14. Muirhead, E. E., and Hill, J. M., The advantages and clinical uses of dessicated plasma prepared by the adtevac process. Ann. Int. Med., 1942, 16, 286.

15. Ashworth, C. T., Muirhead, E. E., and Hill, J. M., Effect of hypertonic plasma on the body fluids in normal experimental animals. Am. J. Physiol., 1942, 136, 194.

16. Cohn, E. J., The plasma proteins: their properties and functions. Tr. \& Stud., Coll. Physicians, Philadelphia, 1942, 10, 149. 